\title{
ENSINO MÉDIO: EXPECTATIVAS E REPERCUSSÕES NO PROJETO DE VIDA DAS JUVENTUDES DO IFPE
}

\begin{abstract}
José Nildo Alves Cau
Ramon de Oliveira

DOI: doi.org/10.15628/geoconexoes.2019.3544

\section{RESUMO}

A pesquisa faz parte do estudo de doutorado em Educação na UFPE, que visa analisar como o Instituto Federal de Educação, Ciência e Tecnologia de Pernambuco contribuiu através das relações vivenciadas, no processo formativo dos jovens egressos da Educação Profissional Técnica de Nível Médio para as suas escolhas e mediações para a materialização do projeto de vida. Para tanto, realizamos um estudo exploratório com 390 sujeitos dos campi de Belo Jardim, Barreiros e Vitória de Santo Antão com a finalidade de caracterizar o perfil socioeconômico dos jovens/alunos matriculados no curso Técnico Integrado de Agropecuária do IFPE $\left(1^{\circ}, 2^{\circ}\right.$ e $3^{\circ}$ anos) e desvelar as expectativas de projeto de vida da juventude do IFPE, considerando a continuidade dos estudos, inserção no mundo trabalho e a vivencia da cidadania juvenil enquanto finalidades da EPTNM. As expectativas apontam para uma indefinição e uma imprevisibilidade em relação ás perspectivas para o projeto de vida que na sua maioria assinalam para continuidade do processo escolarização.
\end{abstract}

Palavras-chaves: EPTNM, Juventude, Projeto de vida.

\section{ABSTRACT}

The research is part of the doctoral study in education at UFPE, which aims to analyze how the Federal Institute of Education, Science and technology of Pernambuco contributed through the experienced relations in the formative process of the young graduates of Vocational Education Middle Level technology for their choices and mediations for the materialization of life project. To this end, we conducted an exploratory study with 390 subjects of the campuses of Belo Jardim, Barreiros and Vitoria de Santo Antao in order to characterize the socioeconomic profile of young people / students enrolled in the IFPE Integrated Technical Course of Agriculture (1st, 2nd and 3rd years) and unveil the life project expectations of IFPE youth, considering the continuity of studies, inclusion in the labor world and the experiences of youth citizenship while purposes of EPTNM. Expectations point to uncertainty and unpredictability about the prospects for the life plan that mostly signal for continuity in the schooling process.

Keywords: EPTNM, Youth, Life project. 


\section{INTRODUÇÃO}

O artigo é parte inicial do estudo de doutoramento em Educação na UFPE que visa analisar como o Instituto Federal de Educação, Ciência e Tecnologia de Pernambuco contribuiu e mediou através das relações vivenciadas no processo formativo dos jovens egressos da Educação Profissional Técnica de Nível Médio, nas suas escolhas para a materialização do projeto de vida. No estudo exploratório envolvemos 390 sujeitos objetivando caracterizar o perfil socioeconômico e o modo de ser dos jovens matriculados no curso Técnico Integrado de Agropecuária do IFPE ( $1^{\circ}, 2^{\circ}$ e $3^{\circ}$ anos), bem como, desvelar as expectativas de projeto de vida da juventude do IFPE, considerando o quadro avaliativo da continuidade dos estudos, inserção no mundo trabalho e a vivencia da cidadania juvenil, enquanto finalidades da EPTNM ${ }^{14}$, nos campi de Belo Jardim, Barreiros e Vitória de Santo Antão. Fomentamos com isso reflexões em torno do contexto do Ensino Médio e as mediações no processo de formação da juventude (s) e as expectativas alimentadas quanto ao rumo após concluir essa etapa da sua vida.

Almeja-se com este estudo conhecer e compreender o fenômeno social que envolve as relações estabelecidas no processo formativo enquanto propósitos do ensino médio e sua repercussão na formação dos jovens para elaboração do seu projeto de vida. Considerando para tal finalidade, a delimitação do contexto prescrito para a EPTNM no IFPE como espaço que tem repercutido a democratização do acesso à última etapa da educação básica, para materialização de uma proposta que tem como finalidade preparar as novas gerações para a apropriação do trabalho, da cultura e da ciência.

Nesteestudo aborda-se o processo de produção social da juventude, que ajuda a captar as materialidades e imaterialidades que emergem do cenário contemporâneo, nas suas diferentes esferas sociais, as quais constituem a realidade concreta das juventudes, e que representa um contingente social mais diretamente exposto aos dilemas da sociedade, expresso como "um grupo que os torna visíveis para sociedade como um todo" (MELUCCl, 1997, p. 8). Os jovens podem informar alguma coisa sobre os vetores e linhas de força que desestabilizam campos sociais prévios, ou redefinem, deslocam suas fronteiras, abre-se para outras e também traçam as linhas que desenham as novas figuras da trajetória social. (TELLES, 2006).

Dessa forma, reconhece-se como essencial trazer para a arena de debates as temáticas da juventude e do ensino médio, uma vez que é preciso debruçar-se na realidade da última etapa da educação básica, como forma de melhor compreender as questões de ordem estrutural, mas, principalmente, captar quem são esses sujeitos sociais, quais as expectativas, os interesses, que desejos são alimentados no processo de organização do projeto de vida, "quanto ao rumo na vida".

O estudo aponta para a necessidade de reflexão de que a escola por si só não consegue dar conta de alimentar as esperanças de milhares de jovens, com um presente demarcado de necessidades e vulnerabilidades e que não podem esperar por um futuro para almejar o sucesso, pois necessitam sobreviver. Para tanto, "olhar para esse fenômeno pode auxiliar-nos a desvendar sua essência, seja recorrendo à ênfase nos processos de construção identitária da juventude, seja recorrendo às questões de caráter mais estruturante" (COSTA; KOSLINSKI, 2006). 


\section{ENSINO MÉDIO E A FORMAÇÃO DOS JOVENS FILHOS DA CLASSE QUE VIVE DO TRABALHO}

Compreende-se no estudo que o processo de democratização e a luta pela universalização da Educação no Brasil, os jovens filhos da classe que vive do trabalho, ascende à garantia de acesso à escolarização e tem depositado a essa condição a possibilidade de mobilidade socioeconômica, atribuindo a etapa final da educação básica, como essencial para a preparação da travessia para vida adulta.

Nesse ensejo, conhecer os determinantes sociais que têm interferido na materialidade do ensino médio passa por compreender a realidade posta pela concretude, como uma condição a ser buscada no processo investigativo, sobretudo porque ele representa uma etapa importante na formação dos jovens. Contudo, as mudanças ocorridas no panorama educacional apontam, por um lado, para a expansão do acesso das classes populares a essa etapa do ensino e que vem ganhando contornos nos índices de ampliação das matrículas na faixa de 15 a 17 anos. Entretanto, essa realidade não tem refletido positivamente nos índices de avaliação, pois tem demonstrado na sua concretude a falta de sentido da escola, no abandono e na evasão escolar, expressando com isso os baixos índices de avaliação do desempenho da aprendizagem dos jovens, de maneira especial nas escolas públicas.

Reportamo-nos aos movimentos políticos de alternância da ditadura para democracia que trazem para a arena do debate os movimentos políticos e sociais na construção de marcos normativos, como a Constituição de 1988 e a nova Lei da educação. No processo de embate e lutas políticas, oito anos se passaram para a aprovação da LDB (Lei n. ${ }^{0}$ 9.396/96); consolidando no seu artigo 22 a atribuição de que a "Educação básica tem por finalidade desenvolver no educando, assegurar-lhe a formação comum indispensável para o exercício da cidadania e fornecer-lhe meios para progredir no trabalho e em estudos posteriores" (FRIGOTTO, et al., 2014, grifo nosso).

Compreende-se que o Ensino Médio corporifica a noção de trabalho e cidadania como fundamento para a formação dos jovens, constituindo-se como Educação Básica, tomando como base norteadora, os pressupostos estéticos, éticos e políticos que são os pilares da Constituição Federal e a LDB. Entende-se como finalidade do ensino médio:

Art. 350 Ensino Médio, etapa final da Educação Básica, com duração mínima de três anos, terá como finalidade: I - a consolidação e o aprofundamento dos conhecimentos adquiridos no Ensino fundamental, possibilitando o prosseguimento dos estudos; II - a preparação básica para o trabalho e a cidadania do educando, para continuar aprendendo, de modo ser capaz de se adaptar com flexibilidade a novas condições de ocupação ou aperfeiçoamento posteriores; III - o aprimoramento do educando como pessoa humana incluindo a formação ética e o desenvolvimento da autonomia intelectual e do pensamento crítico; IV - a compreensão dos fundamentos científicotecnológicos dos processos produtivos, relacionado à teoria com a prática, no ensino de cada disciplina. (BRASIL, 1996, p.28). 
Com isso, destaca-se que a identidade da escola de ensino médio tem como função contribuir para uma formação que desperte nos jovens as capacidades necessárias para questionar, criticar, refletir a realidade e estabelecer as devidas leituras de mundo. Contribuindo para a formação que valorize a heterogeneidade e na direção da superação de um padrão cultural regulador. Por outro lado, localiza-se que a realidade concreta tem focado que grande parte dos discursos normativos sobre as relações do Ensino Médio e a juventude tem sido apontada para invisibilidade dos sujeitos do processo formativo.

Com as mudanças operadas no ensino médio, ao longo do século XX e no início do século XXI, os jovens que chegaram à escola e deveriam ser o centro de atenção, não foram abarcados como um problema a ser resolvido com ações efetivas. Em outras palavras, não se apreende nos estudos o jovem existente no aluno, como assinalado por Carlos Brandão (apud DAYRELL, 2012, p. 299, grifos nossos), da necessidade de mergulhar na compreensão "não apenas o mundo cultural do aluno, mas a vida do jovem em seu mundo de cultura, examinando as suas experiências cotidianas de participação na vida, na cultura e no trabalho". Nessa direção Frigotto (2004, p. 38) contextualiza:

\footnotetext{
Os alunos do ensino médio não se tratam, pois, de sujeitos sem rosto, sem história, sem origem de classe ou fração de classe. Os sujeitos a que nos referimos são predominantemente jovens e, em menor número, adulto, de classe popular, filhos de trabalhadores assalariados ou que produzem a vida de forma precária por conta própria, do campo e da cidade, de regiões diversas e com particularidades socioculturais e étnicas. É sob essa realidade de tempos e espaços diversos de sujeitos coletivos (jovens e adultos) reais que podemos construir (...) uma política de ensino médio que resgate o direito a continuação do processo de escolarização para aqueles a quem isso foi negado até o presente [...]. Trata-se de sentidos e significados que afetam a forma, o método e o conteúdo e o conteúdo do ensino médio.
}

Nesse contexto histórico, as reformas educacionais retratam a lógica hegemônica, cuja direção e as bases ideológicas prescritas estão a serviço dos interesses do capital, como exigência de que tipo de sujeito, na forma e no conteúdo, deve ser conformado à sua lógica, corroborando assim, o modelo econômico nacional de desenvolvimento hegemônico no país, que predominou desde a segunda metade do século XX. Assim, a escola de Ensino Médio assume a função social de formar os jovens para atender às demandas do mercado de trabalho. Gradativamente, a escola foi perdendo sua função exclusivamente propedêutica, com a qual atuava anteriormente.

Pelo exposto, entendemos que a garantia do direito à educação básica de qualidade deve estar em sintonia com a necessidade de uma educação profissional de nível médio, de caráter politécnico, e que "não tem objetivo de preparar o indivíduo para execução de tarefas que Ihe garantam a existência enquanto ser social comandado pela fome, pelo frio ou pela dor, ainda que não se furte a dar a sua contribuição nesse sentido" (BERNARDIM, 2013, p. 99).

Assim, a educação politécnica no seio da luta da classe trabalhadora deve atuar numa direção formativa dos jovens, que possibilite a visão global do trabalho e no pleno desenvolvimento dos seres 
humanos, suplantando a perspectiva de uma educação orientada para o adestramento, a subordinação, a simplificação da atual forma de existência social, que restringe a preparar os sujeitos para o senso comum dominante, como forma de manutenção do status dominante.

Há estudos que comungam de que um dos principais desafios na atualidade para o Ensino Médio é a universalização do acesso a um grande contingente de jovens contemplados com a criação de uma organização política e pedagógica, e garantir as condições materiais e imateriais necessárias para assegurar sua permanência no contexto escolar, possibilitando a apreensão de saberes significativos para todos. Para tanto, faz-se necessária à superação da dicotomia histórica entre trabalho intelectual e trabalho manual para ratificar a direção da formação integrada e a concepção da politécnica, dentro dos pressupostos do trabalho, ciência e da cultura como norte para formação da juventude.

Cabe ressaltar que o estudo se situa nas relações estabelecidas pelo viés das contradições da educação escolar, como foco de disputas ideológicas entre leituras de mundo e projetos de sociedade, que ora se antagonizam, ora se justapõem ou complementam, em cuja realidade tem prevalecido a disputa pelo controle das políticas educacionais que visam alimentar a produção das subjetividades dos jovens, na perspectiva da conformação; sobretudo, com a finalidade de despejá-los no mercado de trabalho, na propagada tarefa de tecnificação crescente, como bem assinala Marcuse no artigo de Belluzzo (2012, p. 1), no sentido de uma "automatização psíquica" dos indivíduos, "onde os processos são substituídos por reações imediatas, simplificadoras e simplistas, quase sempre fulminantes e esféricas em sua grosseria".

\section{OS JOVENS E A ESCOLA DE ENSINO MÉDIO}

Os jovens estabelecem suas relações sociais nos diferentes espaços e tempo de sociabilidade, entre ele, a escola. Cabe assinalar que as escolas vivem o reflexo do processo de democratização da educação e a crescente massificação escolar dos anos 1990, quando abrem as portas da escola para os jovens filhos da classe trabalhadora com toda a sua pluralidade de vivências. A transformação na realidade do ensino médio público no Brasil associa-se a esse processo de massificação do acesso à escolarização. Os jovens trazem para o contexto escolar as marcas dos conflitos e das contradições dos processos de precarização das condições de sobrevivência, ao qual são submetidos nas suas experiências diárias, influenciando, de certa maneira, na construção de sua trajetória escolar. Como afirmado por Dayrell e Carrano (2014, p. 127),

As escolas esperam alunos, e o que recebem são sujeitos de múltiplas trajetórias e experiências de mundo, muitas delas oriundas das redes de relacionamento produzidas nos novos espaços-tempos da internet, dos mercados de consumo, de grupos culturais juvenis ou intergeracionais, de grupos religiosos e de culturas criativas e periféricas. São muito jovens aprisionados no espaço e tempo - presos aos bairros periféricos e com enormes dificuldades para articularem projetos de vida. 
Há uma evidência no contexto escolar expressa na ausência de sintonia entre os interesses estabelecidos no estatuto da escola e a diversidade de estilos juvenis que passa a circular, no ambiente da escola, com a chegada dos jovens das classes populares. Estudos corroboram com duas questões importantes a serem compreendidas: uma relacionada com os elevados índices de abandono escolar e o outro aspecto remete ao processo de esvaziamento do significado do espaço escolar.

$\mathrm{Na}$ atualidade, um dos grandes desafios posto, passa pela escola apreender e reconhecer que o jovem que chega à escola traz toda a sua bagagem de experiências produzidas e apreendidas nos múltiplos espaços da sociedade. Por outro lado, ao entrar no contexto escolar, é submetido ao processo de homogeneização que visa regular os comportamentos prescritos a todos os alunos. Como observado por Dayrell (2011), a condição de aluno é uma alternativa que poderá ser ou não incorporada pelo jovem.

Por essa razão, apontam-se, em diversos estudos, para as implicações nas relações da escola de ensino médio e os jovens/alunos para a ausência de canais de escuta como um dos fatores do distanciamento dos jovens e da escola. Reconhecer também esse afastamento na vivência do cotidiano escolar entre a assertiva da reflexão, pensamento e a vivência da prática social, como possibilidade de aproximar dos interesses dos jovens e as finalidades propostas para etapa tão importante na formação das juventudes.

\section{JUVENTUDE(S): DOS PROBLEMAS AS INCERTEZAS NO RUMO NA VIDA}

Diante do exposto, compreender a realidade da juventude passa por desvelar as imbricações como sujeitos plurais (ABRAMO, BRANCO, 2008), que estabelecem relações sociais com os demais e vão produzindo sua subjetividade como o resultado das vivências ao longo da sua trajetória de vida. Considerando que pensar a juventude hoje é, na verdade, encontrar a diversidade que implica sua condição social de classe, e significa mergulhar em uma conjunção de sujeitos reais, com experiências, desejos, vontades, contestações, escolhas e dilemas demandados da condição juvenil contemporânea.

Compreende-se a categoria juventude como construída socialmente e caracterizada conforme o contexto sócio histórico em que os sujeitos sociais estão inseridos. Considerando que essa abordagem garante estabelecer o sentido de que a problemática da juventude deve ser compreendida como um fenômeno social, cultural e não meramente natural (CATANI, 2008). Ou, simplesmente, uma categoria singular que é incorporar padrões culturais como uma condição genérica a todos os sujeitos que denota um viés funcionalista em concebê-los.

Há uma diversidade de Juventude(s), e diferentes atenuantes, que deve ser considerada para a compreensão da condição juvenil, ${ }^{15}$ considerando os jovens negros, pobres, mulheres e homens jovens, das áreas urbanas e do meio rural, que são submetidos aos mais diversos processos de exclusão, pelas poucas oportunidades de escolarização, pela falta de empregos, restritos ao campo de vivência social, que se traduzem em parcas condições de inserção socioeconômica, inviabilizando, assim, as 
potencialidades da juventude em vivenciar e experimentar as formas qualificadas de sociabilidade, como evidenciado em estudos realizados por Carrano e Dayrell (2014) e Dayrell, Leão e Reis (2011),

Nesse sentido, compreende-se que a escolha da escolarização dos jovens filhos da classe que vive do trabalho é um fato construído histórica e socialmente, e que teve seu horizonte demarcado pela "desnecessidade" de escolarização para classe menos letrada, mas como algo "natural" para o segmento social advindo da classe burguesa privilegiada, como um instrumento de prescrição de uma civilidade herdada e atribuída pela sociedade regulada para a recompensa socioeconômica no futuro (BERNARDIM, 2013).

Esse paradigma está presente, no contexto da escola futurista, sinalizando uma transição da juventude para a vida adulta, a qual institui uma sociabilidade regulada e que deposita no futuro o tempo da recompensa, ou seja, a expressão de uma condição social de adulto definida, em grande parte, "à mera idealização ou projeção do conjunto de elementos que determinada pela sociedade espera de seus membros reconhecidos como plenamente desenvolvidos e integrados no auge da vida coletiva e institucional" (CATANI; GILIOLI, 2008, p. 99); caracterizando como horizonte para a manutenção de um status social e a garantia do acesso à "terra prometida" traduzido no diploma e na recompensa no futuro.

A perspectiva de mobilidade social que almejava na modernidade não encontra mais a linearidade demarcada na previsibilidade como traços determinantes de uma transição ${ }^{16}$ entre infância e a vida adulta. Incorporar-se uma nova leitura assentada na complexidade da sociedade contemporânea, como bem apresenta Hall (2000) à concepção de sujeito pós-moderno vem quebrar essa estabilidade e previsibilidade para a própria característica de mudança permanente da história humana, destacando - "tudo que é sólido se desmancha no ar [...]." (HALL, 2000, p. 14). Como uma vestimenta, o sujeito escolhe a ocasião mais adequada para usar uma das suas diversas identidades.

Mergulhar na realidade subjacente às últimas décadas do século XX e entrada do século XXI, depara-se uma série de contradições que configura um quadro de um futuro nebuloso para a juventude brasileira ${ }^{17}$, considerando os aspectos econômico-sociais, culturais, políticos e educacionais que demandam um olhar muito além das aparências propagadas pelos profetas do mercado. Expressa num cenário de extrema desigualdade social, em que a maioria das vítimas tem sido os jovens filhos da classe trabalhadora.

Frente à realidade comungamos da reflexão de que a escola por si só não consegue dar conta de alimentar as esperanças de milhares de jovens, com um presente demarcado de necessidades e vulnerabilidades e que não podem esperar por um futuro para almejar o sucesso, pois necessitam sobreviver.

Situa-se a dimensão do trabalho como um dos pilares importantes nesse momento da formação da juventude, sobretudo, no desafio da escola reconhecer a sua centralidade, para o processo de formação dos jovens do ensino médio, "sem confundir isso unicamente com a defesa da educação

16 Ver a definição do termo transição (WELLER, 2014, p. 137).

17 O segmento de jovens negros/as tem sido vitimado e tem se ampliado na década, partindo de 45,8 em 2002 e chegando ao índice de 82,7 em 2006 e atingindo o patamar de 139,1 em 2010 (WAISELFISZ, 2012, p. 63). 
profissional (as coisas não são sinônimas), parece ser necessário aprofundar as conexões entre a escola e o mundo do trabalho, como um direito essencial para cidadania juvenil" (CORTI, 2010, p.15).

\section{RETRATO DOS JOVENS DO IFPE: EXPECTATIVAS E INCERTEZAS NA CONSTRUÇÃO DO PROJETO DE VIDA}

No cenário da sociedade contemporânea apresenta-se inscrito de incertezas e de futuro im'previsível'. Para Camarano et al. (2004, p. 13) assinalam: "Há indicações de que uma parcela importante dos jovens brasileiros está, atualmente, experimentando uma série de fragilidades e vulnerabilidades, o que leva a que se fale em uma 'crise dos jovens'." Nesse sentido, essas autoras afirmam que em decorrência desse processo de instabilidade:

\footnotetext{
[...] acredita-se que esse grupo tem passado mais tempo na casa dos pais na condição de dependentes. Além da dificuldade de inserção no mercado de trabalho, esses jovens estão experimentando maior instabilidade nas relações afetivas - casamento e descasamento -, muitas jovens ainda nos seus teen estão optando pela fecundidade precoce como uma forma de inserção no mundo adulto. (CAMARANO et al., 2004, p. 13).
}

Conforme Weller (2014) reitera que há contornos diferenciados quando relacionados com os marcadores sociais do processo de transição, e afirma:

\footnotetext{
É importante, além disso, termos em mente que as formas e os tempos de transição não são os mesmos entre os jovens do sexo feminino e do sexo masculino, para os jovens negros, do meio rural, do meio urbano que residem em bairros periféricos e para jovens cujos pais não tiveram acesso às etapas mais avançadas da educação básica. (WELLER, 2014, p. 137).
}

No horizonte da formação humana, as experiências vividas pelos jovens, ao longo dessa etapa formativa, devem configurar-se para a construção do projeto de vida, em que se toma como leitura a compreensão de Dayrell et. al. (2011) e Velho (2003). Para tanto, compreendemos que os jovens ao longo da sua vida vão construindo e reorganizando seu projeto, como resultado das relações interpessoais e das experiências socioculturais constituídas através da vida cotidiana situados nos tempos e nos espaço sociais.

De acordo com Velho (2003), compreende-se como projeto de vida um processo sistemático e reelaborado, que reorganiza a memória do ator, dando novos sentidos e significados, provocando, com isso, repercussões na sua identidade; cujo projeto, pode ser a representação de conceitos, palavras, categorias, seria um instrumento básico de organização desses fragmentos e de negociação da realidade com outros atores sociais nas suas relações individuais e coletivas. 
Exatamente, essas condições marcam diferentes esferas da vida social da juventude preconizando os aspectos sociais, econômicos, culturais, ora apresentando fortes marcas da modernidade, ora fortes nuances das sociedades tradicionais, ora marcadas por aspectos culturais globais, ora locais.

Com isso tomamos como subsídios para o debate acerca de projeto de vida, as contribuições apontadas nos estudos de Viana (2012) que assinala para uma leitura mergulhada nas bases filosóficas de Marx e Sartre na elaboração de um esboço teórico sobre a temática. Cujas concepções nos permitem pensar a definição de projeto de vida, embora reconheça que o Marx não fez uso da terminologia, mas ratificar o caráter teleológico consciente do ser humano é a intencionalidade, finalidade, produzidas na mente para depois transformar em ação. Já nos estudos de Sartre assinalam que o projeto de vida é essencialmente o querer, no contexto das escolhas dos sujeitos ${ }^{18}$ (Ibidem). Em síntese, os estudos de Viana apontam para uma definição de projeto de vida que nos ajudam a compreender o terreno deste estudo.

Dessa maneira, o mesmo autor atribui como sendo o projeto o elemento que vai além da palavra de uso comum, na sua diversidade de sentidos como o que os indivíduos querem realizar, seus planos para desenvolver suas atividades. Com isso, assinala que

O projeto é o querer e a intencionalidade dos indivíduos na realização de suas atividades e ações em geral. 0 projeto de vida, por conseguinte, é aquilo que os indivíduos querem, intenciona, fazem com suas vidas. Aqui o significado é mais profundo, pois tem a ver como uma opção de vida, uma intencionalidade não para realizar uma tarefa determinada por pressões sociais ou por necessidades impostas do exterior. Trata-se uma determinada forma de pensar sua existência num sentido ideal (uma intencionalidade ou querer que revela uma reflexão e consciência sobre o que quer realizar e como fazê-lo) que se busca concretizar, no sentido mais amplo em relação á sua vida como um todo. Isto se assemelha á ideia do primeiro Sartre de "escolha original" ou "projeto original", que é o fundamento de todas as escolhas e que no segundo Sartre será uma "escolha situada". Essa concepção também expressa o que em Marx pode ser chamado de práxis, o trabalho como objetivação, manifestação ou autor realização do ser humano, processo pelo qual ele se autor reproduz, ou seja, se reproduz de forma teleológica e consciente. (VIANA, 2012, p.6).

Nesse sentido sinalizamos com uma das possibilidades de leitura de concepção de projeto de vida, algo que não temos a pretensão de esgotar nesse artigo, uma vez que está questão não tem se apresentado como consenso nos estudos produzidos acerca da abordagem da temática de juventude e as suas escolhas. Por outro lado, demarcamos uma posição quando comungamos da compreensão de que o projeto de vida vai muito mais além das posições e reflexões apresentadas nos debates

18 Ver estudos de Sartre após $2^{\circ}$ Guerra que aproxima do marxismo com a publicação Crítica da razão dialética e que trata da "Escolha situada". 
sobre juventude e que tem atribuído um viés reducionista de projeto atrelado a "projeto profissional" as possibilidades de inserção dos jovens ao mercado de trabalho ou das aptidões profissionais para determinado sentido ecoado pelo megafone do mercado e disseminado de forma mais efetiva pelo campo da psicologia. "Essa perspectiva significa limitar a apenas determinados setores da juventude que possuem projetos de vida alienados, ou seja, determinados pela sociedade (em suas diversas instâncias, meios oligopolista de comunicação, Estado, discursos científicos) ${ }^{19 "}$ (VIANA, 2012, P.15).

\subsection{CAMINHO METODOLÓGICO}

No estudo exploratório objetivamos conhecer quem são esses jovens que buscam no IFPE as mediações da prática social por meio de sua vivência, seus conhecimentos e suas finalidades e que alimentam suas expectativas na produção social do seu projeto de vida. Partimos da premissa de captar as leituras necessárias sobre esses jovens que chegam à escola, cuja concretude perpassa em compreender como o modo de ser jovem materializa socialmente.

O caminho metodológico organiza-se na conjunção de métodos, técnicas e instrumentos de pesquisa em uma abordagem que articula dados qualitativos e quantitativos, cujo sentido prima em captar e interpretar, à luz dos objetivos, os conteúdos das relações estabelecidas na vida social. Utilizamos como critério de escolha dos sujeitos do estudo ser Alunos/Jovens do $1 .^{\circ}$ ao $3 .^{\circ}$ ano, matriculados no Curso Técnico Integrado de Agropecuária, dos Campi do (IFPE), Belo Jardim e Vitória de Santo Antão em função da finalidade da pesquisa de caracterizar o perfil socioeconômico dos jovens e, assim, desvelar a condição juvenil da juventude do IFPE, considerando para tal, as características de escolarização, gênero, faixa etária, cor, arranjos familiares, formas de participação, sociabilidade juvenil e desejos. Ao mesmo tempo, almeja-se desvelar as expectativas, os desejos e sonhos relacionados com o projeto de vida, "rumo na vida."

Com isso, utilizamos nessa etapa do estudo o instrumento metodológico do questionário, onde aplicamos 390 e recebemos 311 dos jovens matriculados e frequentando o ano letivo de 2014. Desses, havia uma composição de 261 jovens do Campus Belo Jardim representando $84 \%$ e 40 do Campus Vitória representando $13 \%$. Os dados na composição por série, em relação ao universo pesquisado apontam que 115 cursam o $1 .^{\circ}$ ano (37\%); estão no $2 .^{\circ}$ ano 118 (38\%) e 77 estão no $3 .{ }^{\circ}$ ano (25\%).

\section{APROXIMAÇÕES DO PERFIL SOCIOECONÔMICO DOS JOVENS PESQUISADOS}

Os dados revelados dos jovens aponta que grande parte dos jovens é remanescente de rede pública de ensino e está dentro da faixa etária/escolaridade do ensino médio.

Há uma configuração dos arranjos familiares que evidenciam (68\%) residem com os pais e (23\%) com os avós e os demais com outros parentes. 0 estado civil da maioria é de solteiro o que evidencia a tendência de dependência dessa etapa da vida para os jovens; 
Evidenciou que (55\%) dos pais dos jovens não conseguiram concluir a educação básica, nunca estudaram (10\%) e concluiu EM (28\%) e (12,5\%) Ensino Superior, assinalando, o aumento da escolaridade dos filhos em relação aos pais. Mas também há uma evidencia do aumento da escolaridade das mães em relação ao nível de escolaridade dos pais, uma tendência já apontada em estudos.

Constatamos (59\%) tem acesso a computador com internet em casa, $(15 \%)$ só a computador e (23\%) não tem acesso. Quanto à forma participação (46\%) participam de grupos de igreja e $(21,5 \%)$ de grupos diversos e (24\%) não participam; Quanto ao acesso à cultura quase $80 \%$ nunca foi ao teatro, (50\%) já foi ao cinema e (45\%) nunca frequentaram. Quanto às formas de ocupação do tempo livre evidenciou as práticas esportivas, viajar com a família, sair com os amigos, ler, dançar e ouvir música, etc.

Os assuntos que mais interessam aos jovens evidenciaram os estudos, família e futebol e o que as mais preocupam remetem para a saúde, educação e a perspectiva de futuro; Essa realidade remete aos resultados já apontados na pesquisa Agenda Juventude Brasil ${ }^{20}$ que apresenta o perfil e opinião dos jovens brasileiros em 2013. De maneira geral os jovens assinalam preocupação em relação as problemáticas destacadas e que precisam serem atacadas, pois tem repercussão direta na melhoria de condição da vida da população brasileira, como qualidade da educação, saúde e a influência do momento em relação ao fenômeno social o futebol.

\subsection{EXPECTATIVAS APÓS CONCLUIR O ENSINO MÉDIO}

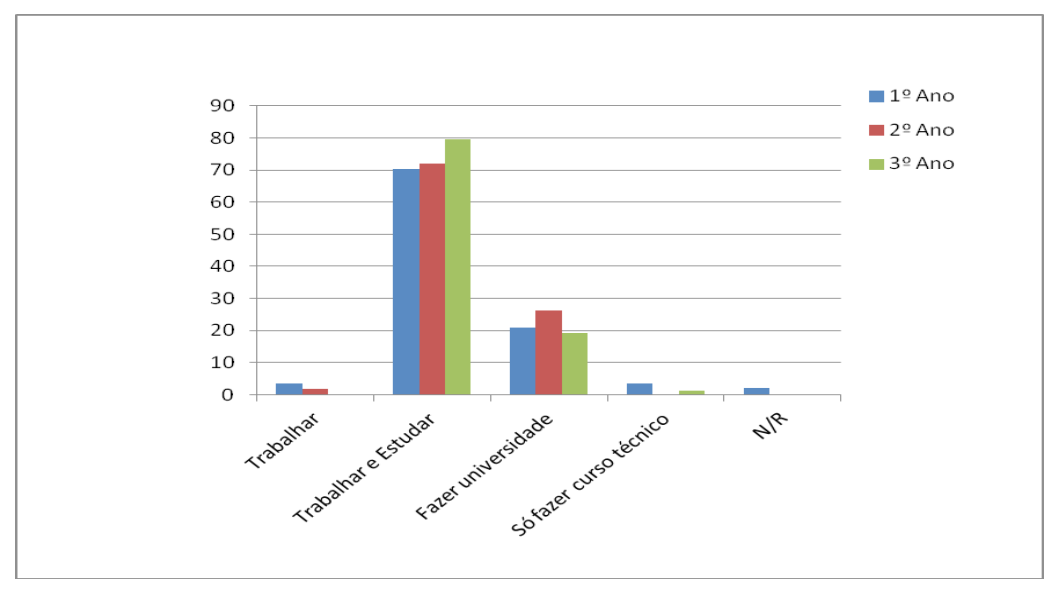

Grafico 1: Expectativas dos jovens após concluir ensino médio Fonte: (0 autor, 2017).

Constatou-se, grande parte dos jovens (73\%) alimentam como expectativa trabalhar e estudar. Em seguida, 22\% pensam em fazer universidade; só fazer curso técnico e trabalhar $2 \%$ e (1\%) não respondeu à referida questão. Essa tendência de estudar e trabalhar se faz presente na grande maioria dos jovens filhos da classe que vive do trabalho, considerando a importância da dimensão do trabalho 
como sentido para a escolarização dos jovens, fator esse que tem sido negligenciado no currículo escolar, conforme expostos nos estudos de Corti (2010).

Deve-se considerar que a condição juvenil só é vivida pela maioria dos jovens da classe trabalhadora porque trabalham garantindo o mínimo de recursos para o lazer, o namoro ou consumo. Normalmente a iniciação ao trabalho ocorrer na adolescência, por meio de 'biscates', numa instabilidade que tende a persistir ao longo da juventude. Essa realidade reitera o trabalho como condição fundamental na vida dos jovens. Ao mesmo tempo, em que a educação aponta como um campo de possibilidade importante de inserção social, mesmo considerando a crise na relação dos jovens e o contexto escolar frente a um estatuto homogeneizado e os novos valores que os jovens experimentam fora dos muros da escola e levam para o cotidiano escolar.

\subsection{QUAIS OS PRINCIPAIS DESEJOS PARA OS JOVENS DO IFPE?}

Evidencia-se como o principal desejo dos jovens para o futuro é "ingressar na universidade" com uma incidência de 111 menções; em segundo, vem à conquista de um bom emprego, com 85 . Em terceiro, aparece "concluir os estudos" com 75, e ainda com uma incidência significativa, evidencia-se "trabalhar", com 67; "constituir família", 44, e ser feliz como uma condição substantiva apresentada pelos jovens. Os achados colocam no visor indícios de que os jovens revelam em seu projeto de vida uma tendência muito presente de marcadores sociais de transição para a vida adulta, que ainda tem configurado em uma perspectiva linear, em depositar no futuro as recompensas da terra prometida, mesmo considerando que tem havido alterações pontuais. Ao tecer uma leitura dos dados abaixo, evidencia-se a importância da escolarização e do trabalho como centrais, na trajetória dos jovens que desejam alcançar, mediante um bom emprego estável, a garantia da tão sonhada autonomia financeira.

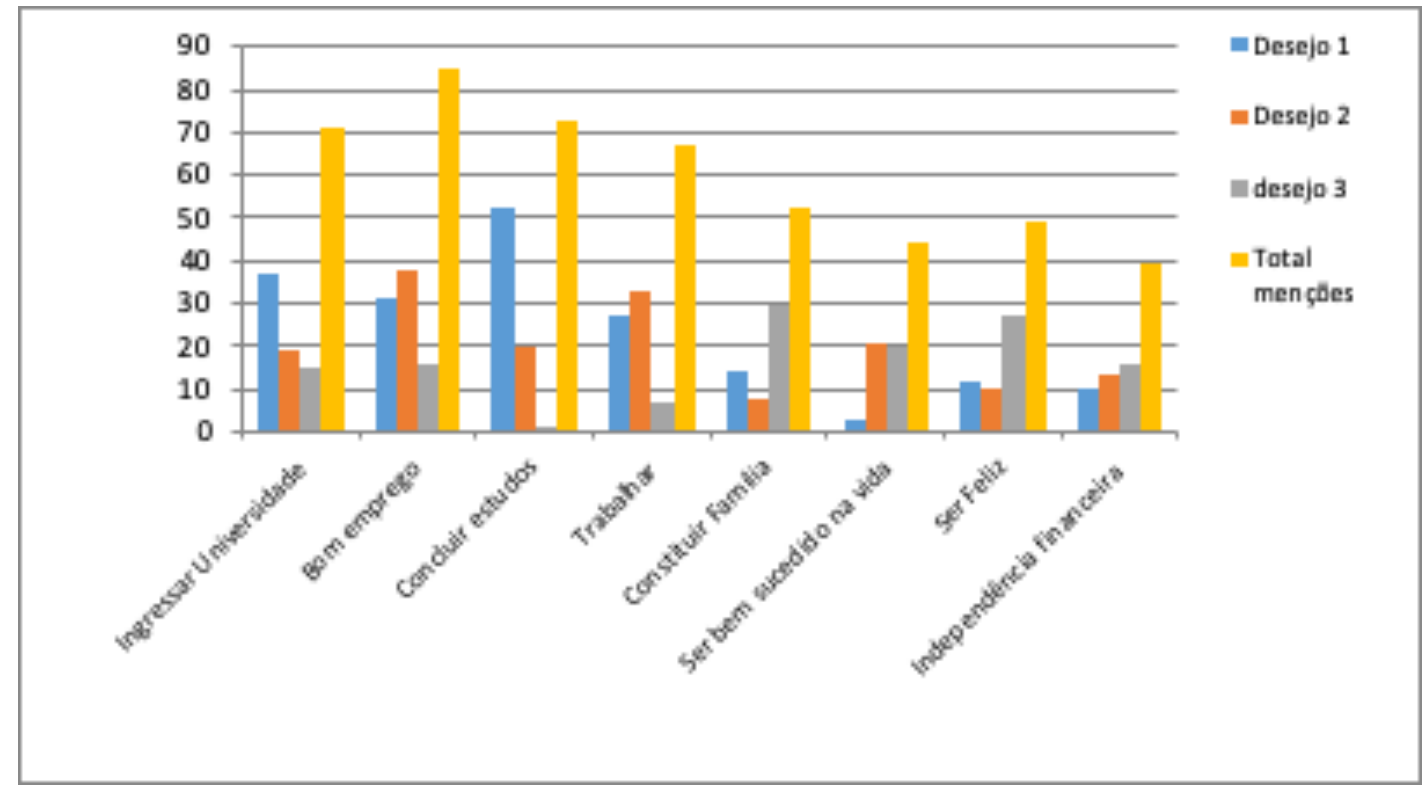

Gráfico 2: Como você se vê daqui a dez anos?

Fonte: (0 autor, 2017). 
Diante das condições postas, a grande maioria dos jovens filhos das classes trabalhadoras tem sido submetida a constrangimentos e determinantes sociais que limitam suas possibilidades de alimentar suas escolhas e expectativas quanto às opções efetivas de construção de novos sonhos. Considerando para isso, a concretude expostas por vários estudiosos assinalando a crise nessa etapa de escolarização e a verdadeira intencionalidade da educação básica ofertada para os jovens/alunos no Brasil. Destacamos que oferta de escolhas e experimentação tem repercutido num universo de muitas incertezas quanto às condições para continuar seu processo de escolarização, na busca pela inserção no mundo do trabalho. Ao mesmo tempo pode usufruir dessa etapa, sobretudo, para que possam alimentar o processo de produção da sua subjetividade desfrutando de uma diversidade de experiências e assim assinalar para novas possibilidades de sociabilidade a que venham fortalecer a cidadania política dos jovens/alunos.

\section{CONCLUSÕES}

Quando olhamos para nosso quadro avaliativo dos pressupostos e finalidades do ensino médio, o cenário dos achados em relação a estudar e trabalhar aponta como uma tendência contrária ao que vem sendo apontado em alguns estudos, cujos jovens alimentam as expectativas ao longo do processo formativo de ingressar na universidade. Evidencia-se nos estudos de Corti (2010) que há uma tendência de associação entre a escola e o vestibular aumentar conforme os alunos progridam nas séries.

Reitera-se que para muitos jovens advindos da classe trabalhadora, cujo contexto do mundo do trabalho para a grande maioria, a experiência ou ausência de experiência, nesse momento da vida apresenta-se de forma diversa. Com isso, uma minoria da juventude privilegiadas de recursos e que estão inseridos no ensino médio, significa um momento de formação para a inserção no mundo do trabalho. Por outro lado, para os filhos da classe que vive do trabalho, representa um tempo de trabalho e de muita "viração" e malabarismo para conciliar a condição de estudante trabalhador.

As expectativas dos jovens refletem uma indefinição e uma imprevisibilidade em relação às perspectivas para o projeto de vida. Com isso, reafirmamos que o processo formativo do Ensino Médio deve configurar-se em uma direção que possibilite abarcar para além dos conhecimentos e saberes "do aluno institucionalizado", mas devemos conhecer o "jovem existente nesse aluno" considerando-se necessários para formação integral, sobretudo na produção das condições essenciais de preparação dos jovens de suas futuras escolhas e na elaboração de seu projeto de vida com seu devido valor social.

Por fim, entendemos que a arena de discussão em relação à juventude e projeto de vida remete diretamente ao processo de produção da existência de um grande contingente de jovens filhos da classe trabalhadora. Com isso, a concretude tem evidenciado cada vez mais a responsabilidade e a necessidade urgente da instituição escola em revisitar seu estatuto e reconhecer esse jovem que chegou, saiu ou que ainda por falta estímulo, permanece no seu contexto educacional sem horizontes, querer, finalidades para a produção de sua existência.

Portanto, os jovens alunos devem ser reconhecidos não somente como sujeitos que tem o direito garantindo a educação básica de qualidade frente aos marcos legal, mas precisa legitimar as suas 
relações e tornar cada mais significativa para os jovens, considerando, enquanto sujeitos que dão sentido a existência da escola e além de tudo, deve oferecer possibilidades e condições de escolhas para que possam serem efetivadas para além de um capital cultural homogeneizado e sintonizado com um mercado excludente. Por outro lado deve contribuir com novos instrumentos e conhecimentos que possam elevar os jovens da condição de senso comum a um nível elevação cultural que possibilitem fazer leitura da realidade e questioná-la.

\section{REFERÊNCIAS}

1. ABRAMO, H. W. BRANCO, Pedro Paulo Martoni. Retratos da juventude brasileira: análises de uma pesquisa nacional. São Paulo: Fundação Perseu Abramo, 2005.

2. BERNARDIM, Márcio Luiz. Juventude, escola e trabalho: sentidos atribuídos ao ensino médio por jovens da classe trabalhadora. 2013. Tese (Doutorado em Educação) - Universidade Federal do Paraná, Curitiba, 2013.

3. BELLUZZO, L. G.. Escola e cidadania. 2012. Disponível em: http://pedagogiapaforxviii.blogspot. com.br/ Acesso em: 19 ago. 2013.

4. BRASIL. Lei n. ${ }^{\circ} 9.394$, de 20 de dezembro de 1996. Estabelece as diretrizes e bases da educação nacional. Diário Oficial [da] República Federativa do Brasil, Poder Executivo, Brasília, DF, 23 dez. 1996a, Disponível em: http://www.planalto.gov.br/ccivil_03/leis/19394.htm. > Acesso em: 19 ago. 2013.

5. CARRANO, P.; DAYRELL, J. Juventude e ensino médio: quem é este aluno que chega à escola. In: DAYRELL, J.; CARRANO, P.; MAIA, C. L. (Org.). Juventude e ensino médio: sujeitos e currículos em diálogo. Belo Horizonte: Ed. da UFMG, 2014.

6. CAMARANO, A. A. et al. Caminhos para a vida adulta: as múltiplas trajetórias dos jovens brasileiros. Última Década, v. 12, n. 21, p. 11-590, dic. 2004.

7. CATANI, A. M.; GILIOLI, R. de S. Culturas juvenis - Múltiplos olhares. São Paulo: Ed. UNESP, 2008.

8. COSTA, Márcio da; KOSLINSKI, Mariane Campelo. Entre o mérito e a sorte: escola, presente e futuro na visão de estudantes do ensino fundamental do Rio de Janeiro. Revista Brasileira de Educação, Rio de Janeiro, v. 11, n. 31, p. 133-154, jan./abr. 2006.

9. CORROCHANO, M. C.. Jovens no ensino médio: qual o lugar do trabalho? In: DAYRELL, J.; CARRANO, P.; M., Carla Linhares (Org.). Juventude e ensino médio: sujeitos e currículos em diálogo. Belo Horizonte: Ed. da UFMG, 2014.

10. CORTI, A. P. de O. Que ensino médio queremos? uma experiência de diálogo com escolas públicas. In: FERREIRA, Cristina A. et al.(Org.). Juventude e iniciação científica: políticas públicas para o ensino médio. Rio de Janeiro: EPSJV, UFPR, 2010.

11. DAYRELL, J.; CARRANO, P.; MAIA, C. L. (Org.). Juventude e ensino médio: sujeitos e currículos em diálogo. Belo Horizonte: Ed. da UFMG, 2014. 
. A escola "faz" as juventudes? Reflexões em torno da socialização juvenil. Educação e Sociedade [online], v. 28, n. 100, p. 1105-1128, 2007. Disponível em: http://www.scielo.br/pdf/es/v28n100/ a2228100.pdf.

DAYRELL, J.;LEÃO, G.; REIS, J. B. dos. Juventude, projetos de vida e ensino médio. Educação e Sociedade, Campinas, SP, v. 32, n. 117, p.1.067-1.084, out-dez. 2011.

12. FRIGOTTO, G.; Juventude, trabalho e educação no Brasil: perplexidades, desafios e perspectivas In: Juventude e Sociedade - Trabalho, educação, cultura e participação - São Paulo, SP: Editora Fundação Perseu Abramo, 2004.

.CIAVATTA, M, RAMOS, M. O ensino médio como problema do presente e como disputa histórica necessária. UERJ, Rio de Janeiro, 2014. (mimeo).

13. GROPPO, Luiz A. Condição juvenil e modelos contemporâneos de análises sociológica das juventudes. ENCONTRO ANUAL DA ASSOCIAÇÃO NACIONAL DE PÓS-GRADUAÇÃO EM CIÊNCIAS SOCIAIS, 30., 2006, Caxambu, MG. Anais... Anpocs, 2006.

14. HALL, Stuart. Quem precisa da identidade. In: SILVA, T. T. (Org.). Identidade e diferença: a perspectiva dos estudos culturais. Stuart Hall, Kathryn Woodward. - Petrópolis, RJ: Vozes, 2000.

15. MELUCCI, A. Juventude, tempo e movimentos sociais. Revista Brasileira de Educação, São Paulo, n. 5/6, p. 5-14, 1997.

16. SARTRE, J-P. Crítica da Razão Dialética. Tomo1. Rio de Janeiro,DP\&A, 2002.

17. TELLES, V. da S. Mutações do trabalho e experiência urbana. Revista Tempo Social, v. 18, n. 1. São Paulo: USP, 2006.

18. VELHO, G. Projeto e metamorfose. Antropologia das sociedades complexas. Rio de Janeiro: Jorge Zahar Editor, 2003.

19. VIANA, Nildo. Juventude, trabalho e projeto de vida. Seminário internacional Juventudes na contemporaneidade. FCS/UFG, 2012, Goiânia. Anais do Seminário - GT Juventude, Trabalho e emprego. http://eventos.ufg.br/sijuc.

20. WELLER, W. Jovens no ensino médio: projetos de vida e perspectivas de futuro In: DAYRELL, J; CARRANO, P.; MAIA, C. L. (Org.). Juventude e ensino médio: sujeitos e currículos em diálogo. Belo Horizonte: Ed. da UFMG, 2014.

21. WAISELFISZ, J.J. Mapa da violência 2012: Novos padrões da violência homicída no Brasil. São Paulo: Instituto Sangari, 2012.

Mapa da violência 2013: homicídios e juventudes no Brasil. Rio de Janeiro: CEBELA/Flacso, 2013. 